\title{
Bleeding Diseases in Orthopedic Clinical Approach
}

\author{
Kadri Yildiz ${ }^{1}$, Vahit Yildiz ${ }^{2}$ \\ ${ }^{1}$ Kafkas University, Medicine School, Kars, Turkey \\ ${ }^{2}$ Adnan Menderes University, Medicine School, Aydın, Turkey
}

\begin{abstract}
Aim Bleeding diseases are rarely studied as complications of an orthopedic surgical procedure with postsurgical bleeding. This study aims to present a retrospective cohort-study about the approach to bleeding disorders in an ordinary orthopedic clinic. Material and Methods 344 patients were recorded for our study group between November 2017 and September 2019. These patients were monitored for bleeding disorders, both primary or secondary. Results 27 (7.84 \%) patients with bleeding diseases [1 (0.29 \%) patient with VWD, 1 (0.29\%) patient with haemophilia, 1 (0.29\%) patient with ITP, 15 (4.36 \%) patients with drug use, 5 (1.45\%) patients with vascular disorders, 4 (1.16\%) patients with herbal agent use] were detected in all traumatic cases which were admitted to our clinic in this time period. These patients were divided in 6 groups. Patient with VWD was Group 1, patient with haemophilia was Group 2, patient with ITP was Group 3, patients with drug use formed Group 4, patients with vascular disorders - Group 5, patients with herbal agent use - Group 6. Conclusion We advise to have a careful preoperative control for postsurgical bleeding risks according to three criteria: i) patient anamnesis should be studied carefully (diathesis/haemophilia searching), ii) platelet counts must be checked (twice is guaranteed), iii) coagulation tests [activated partial thromboplastin time (aPTT), prothrombin time (PT), thrombin time (TT) and International Normalized Ratio (INR)] must be studied.
\end{abstract}

Keywords: bleeding diseases/disorders, VWD), ITP, drugs, herbal therapy, varicose veins

\section{INTRODUCTION}

Bleeding disorders occur in primary and secondary haemostasis defects [1], and are assigned to two main groups: acquired and inherited. Acquired conditions may occur during life, and include liver diseases, vitamin $\mathrm{K}$ deficiencies, warfarin use, and disseminated intravascular coagulation (DIC). The inherited type typically has a genetic predisposition; congenital disorders are divided into three groups, i.e. haemophilia $\mathrm{A}$ and $\mathrm{B}$, Von Willebrand disease (VWD), idiopathic immune thrombocytopenia (ITP), and various clotting factor deficiencies [2]. Oberweis et al. observed that bleeding and thrombotic complications had a frequency of $5.4 \%-5.8 \%$ during hip, knee, and spine orthopaedic surgery [3]. Complication incidences of bleeding diseases are tending to increase. BoltonMaggs et al. recommended that orthopaedists must be careful about diagnoses, treatments, and postoperative complications from bleeding diseases [4].

TWe present a retrospective cohort-study on the clinical examination and approach to bleeding disorders in an orthopaedic clinic. However, bleeding disorders are rarely seen as complications of orthopeadic surgical procedures, with post-surgical bleeding. This condition can cause serious morbidities and mortalities. Orthopaedic surgeons must be cognisant of bleeding diseases, because of persistent bleeding may happen post-surgically.

\section{MATERIAL AND METHODS}

In our trauma centre, we recruited 344 patients between November 2017 and September 2019. These patients were monitored for bleeding disorders for primary and secondary outcomes. 27 patients (7.84 \%) with bleeding disease, one patient $(0.29 \%)$ with VWD, one patient $(0.29 \%)$ with haemophilia, one patient $(0.29 \%)$ with idiopathic immune thrombocytopenia (ITP), 15 (4.36 \%) patients with drug use, five patients (1.45\%) with vascular disorders, and four patients $(1.16 \%)$ with herbal agent use were detected in traumatic cases during this period (Table 1). These patients were divided in six groups; patients with VWD - Group 1, patients with haemophilia - Group 2, patients with ITP - Group 3, patients with drug use - Group 4, patients with vascular disorders Group 5, and patients with herbal agent use - Group 6.

Table 1

Distribution of patients according to bleeding causes

\begin{tabular}{|l|c|c|}
\hline \multicolumn{1}{|c|}{ From a total of 344 } & Patient Counts & Percent \\
\hline Group 1 (VWD) & 1 & $0.29 \%$ \\
\hline Group 2 (Haemophilia) & 1 & $0.29 \%$ \\
\hline Group 3 (ITP) & 1 & $0.29 \%$ \\
\hline Group 4 (Drug use) & 15 & $4.36 \%$ \\
\hline Group 5 (Vascular disorders) & 5 & $1.45 \%$ \\
\hline Group 6 (Herbal agent use) & 4 & $1.16 \%$ \\
\hline Total with bleeding disorders & 27 & $7.84 \%$ \\
\hline
\end{tabular}

Cal Yildiz K., Yildiz V. Bleeding Diseases in Orthopedic Clinical Approachs. Genij Ortopedii, 2020, vol. 26, no 2, pp. 191-197. DOI 10.18019/1028-4427-2020-26-2-191-197 
Bleeding causes were detected as VWD, haemophilia, idiopathic immune thrombocytopenia, drugs, vascular diseases and herbal therapy.

Group 1 (VWD) A 22 year-old male patient with a unilateral/isolated tibial shaft fracture (AO/OTA 42A2) was referred to our emergency service (Fig. 1). No history of haemophilia disease was recorded at anamnesis. After one night, the patient was prepared for tibial nailing of the tibial shaft fracture. During the operation, abnormal bleeding was observed while proximal screws were being placed. At the first postoperative clinical assessment, purpuric rashes, i.e. ecchymosis, were observed on the operated extremity. A hemogram revealed progressive to severe blood loss, i.e. the hemogram range was
8.4-13.37 g/dl, haematocrit (Hct) was $26-41 \%$, and platelets (PLT) were $50,000 / \mathrm{mm}^{3}$ to $121,000 / \mathrm{mm}^{3}$ (Table 1). Coagulation tests and bleeding time tests were normal (Table 2). The patient was further assessed by cardiovascular surgeons and a computed topography angiography (CTA) was performed. The CTA revealed an unclear perforation image (Fig. 2), after which a detailed haematological laboratory investigation was performed (Fig. 3). A VWB Type 2 diagnosis was eventually established (Fig. 4). The patient was transferred to the haematology department. At follow-up, haematological and biochemical tests were performed (Hct: $30.6 \%$ and

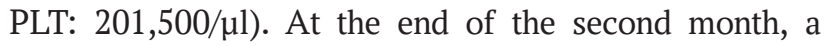
fusion mass was observed in X-rays.

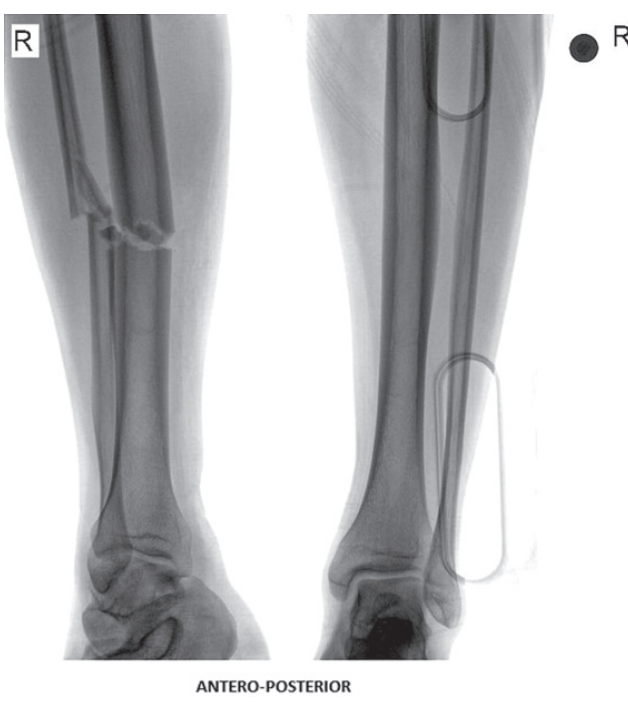
Fig. 1 22-year-old male patient with unilateral/isolated tibial shaft fracture (AO/OTA 42A2)

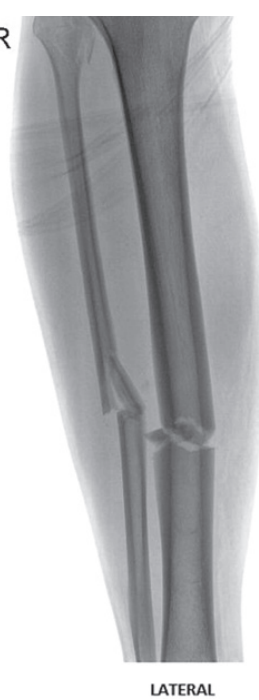
,

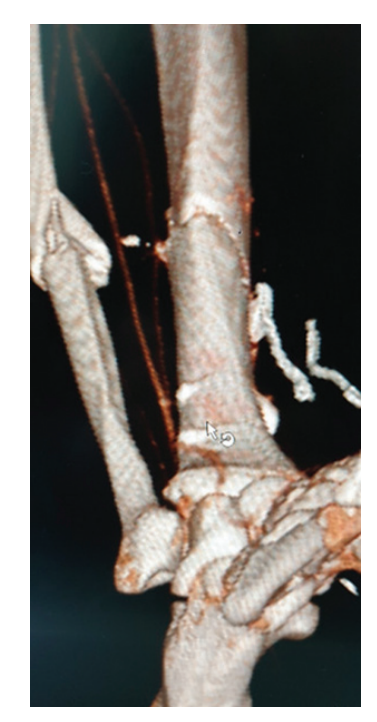

Fig. 2 CTA shows an unclear perforation

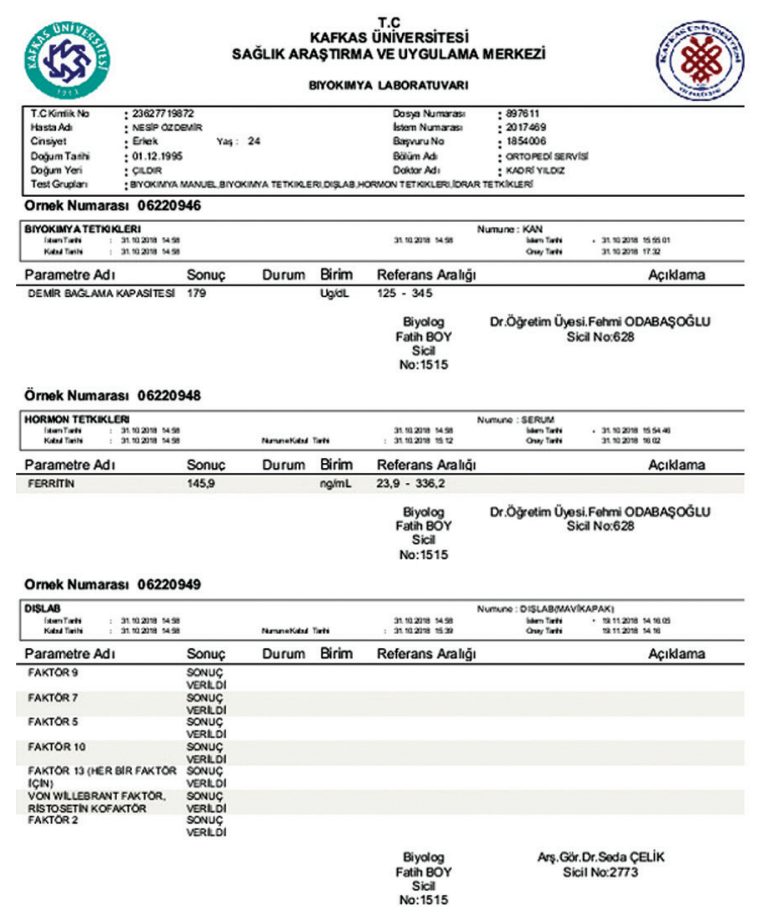

Fig. 3 Haematological laboratory data

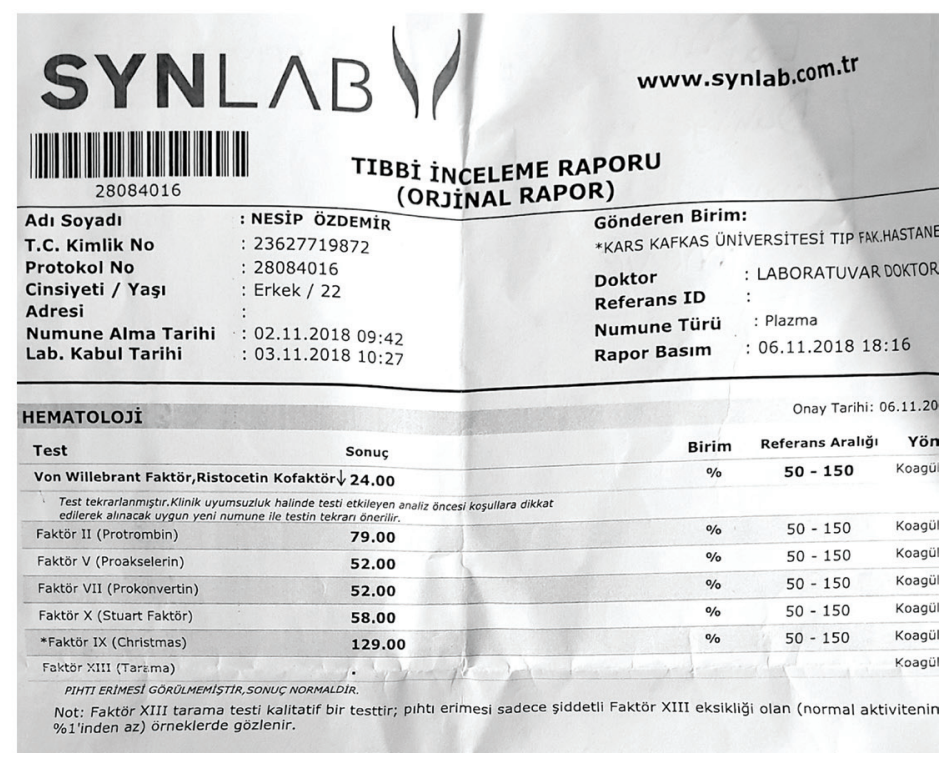

Fig. 4 VWD Type 2 diagnosis 
Group 2 (Haemophilia) A 36 year-old male was diagnosed with haemophilia A (FVIII deficiency) when he was 14 years old (Fig. 5). In his third decade, he increasingly complained of knee pain, with multiple haemarthroses. A bilateral total knee replacement was performed (Fig. 6), and the patient was clinically followed-up.

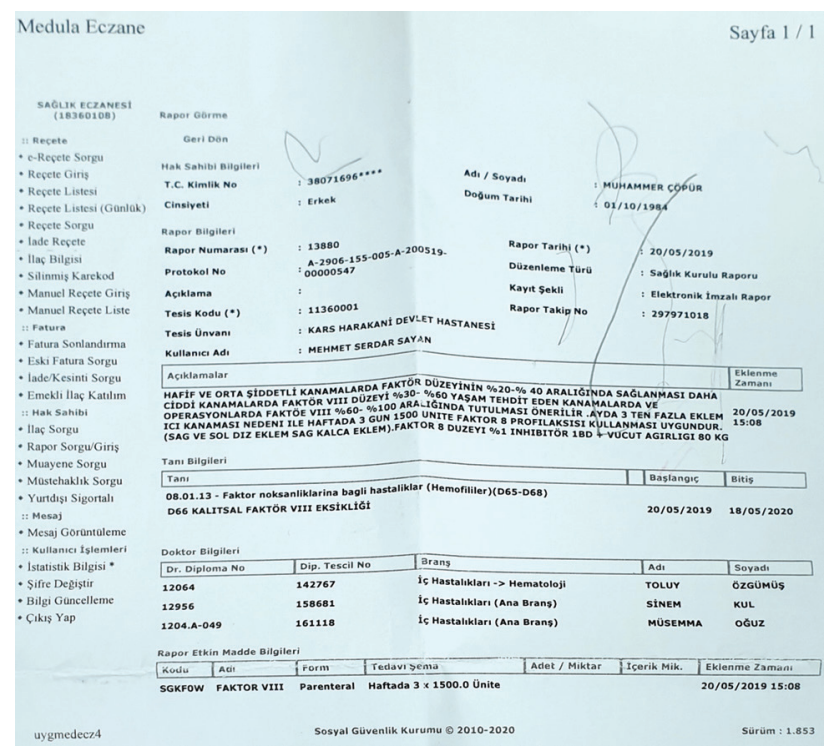

Fig. 536 year-old haemophilia patient's data

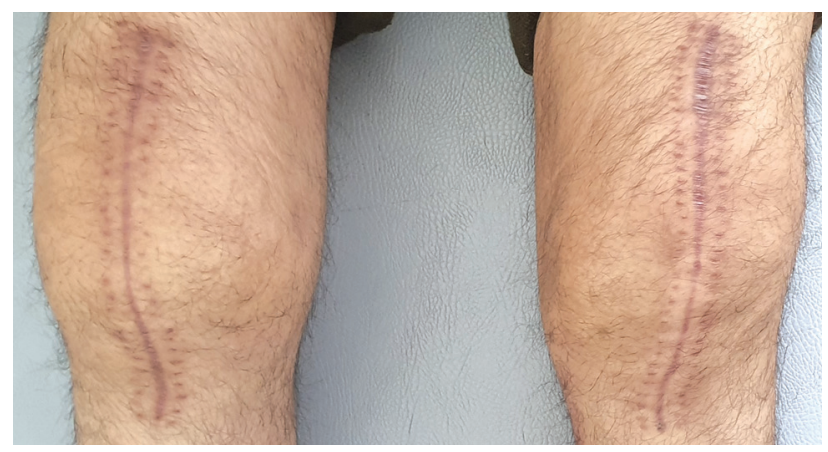

Fig. 6 Bilateral total knee replacements in a 36 year-old haemophilia patient

Group 3 (ITP) A 19 year-old female was brought to our trauma service with a left bimalleolar fracture sustained in a traffic accident, diagnosed as Weber Type 3 (Fig. 7). Patient anamnesis revealed a disease-free status, except her isolated thrombocytopenia was $80,000 / \mathrm{ml}$. After a second review, her PLT count was $77,000 / \mathrm{ml}$. The patient was operated on with two cannulated screws for a medial malleolar fracture and a plate with screws for a fibular fracture. On the second postoperative day, isolated thrombocytopenia was $47,000 / \mathrm{ml}$, and ecchymosis and swelling were observed at the site of the intervention (Fig. 8). The patient was controlled for postoperative bleeding and compartment syndrome for seven days. Medication was applied internally. At clinical follow-up, the patient's extremity had returned to normal.

Group 4 A 59 year-old female patient was operated for proximal humerus fracture and distal radius fracture on the left side (Fig. 9). In the anamnesis of the patient, there was no record about bleeding diseases. Patients and patients' relatives did not inform health professionals about her intake of acetylsalicylic acid
(Coraspin $^{\odot} 100 \mathrm{mg} 30$ tabs, Bayer) 3 days before. On the first postoperative day, there were ecchymosis and swelling in the shoulder area of the patient. On the third day, ecchymosis and swelling subsided (Fig. 10).

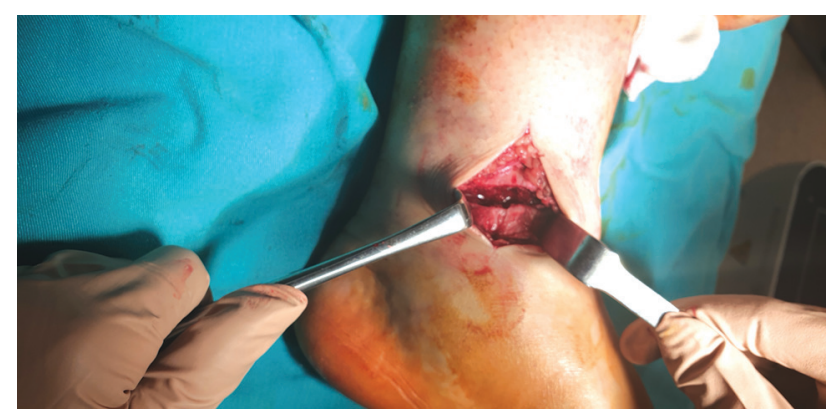

Fig. 719 year-old female with a left bimalleolar fracture, diagnosed as Weber Type 3

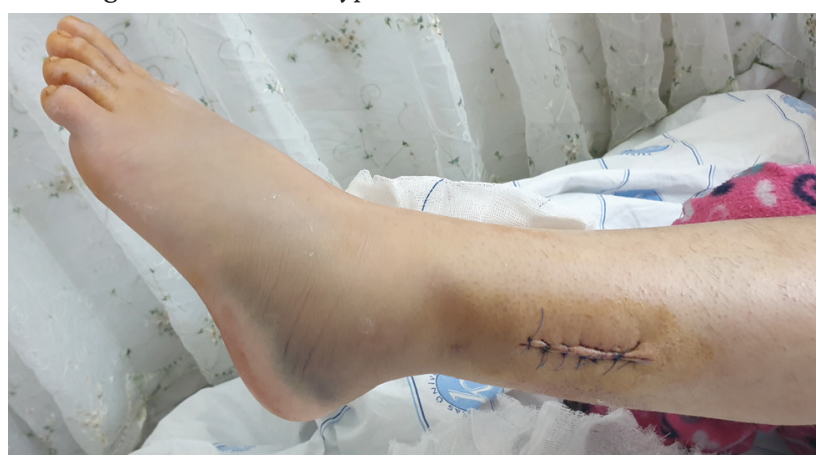

Fig. 8 Isolated thrombocytopenia at follow-up

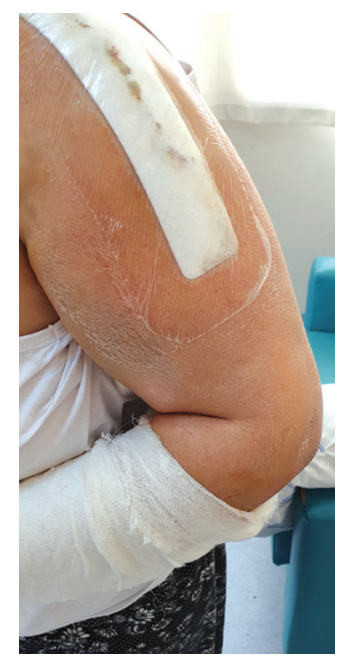

Fig. 959 year-old female with a proximal humeral fracture and a distal radius fracture (left side)

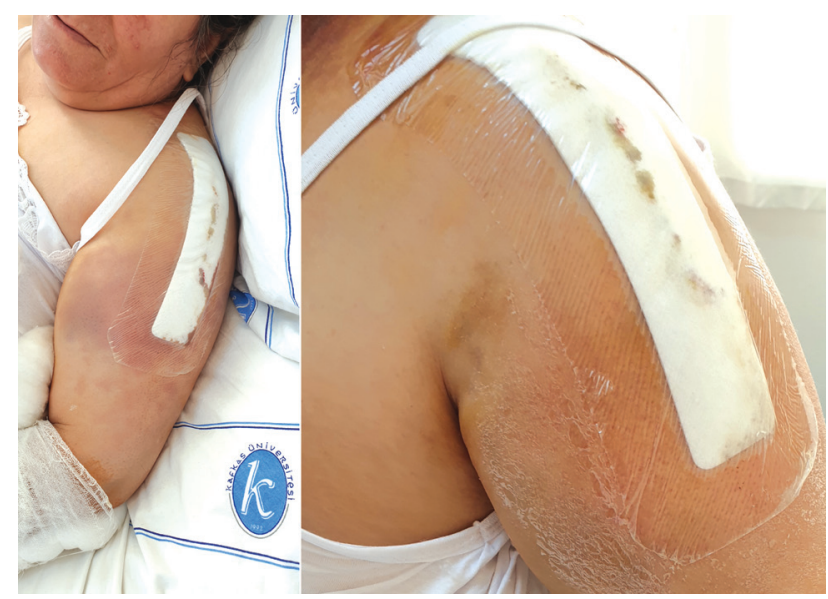

Fig. 10 Preoperative and postoperative ecchymosis, and subsiding swelling 
Group 5 A 71 year-old male with distal tibial fracture (AO/OTA 43A1) after being attacked by a dog was operated by tibial nailing. He had no history of bleeding diseases. The varicose veins of the broken leg were noted before the operation. Sixth hours after the operation, there was little bleeding seen as infiltration. The patient was brought to the operating room 24 hours after due to disturbing bleeding symptoms. Varicose veins were cauterized at the proximal screw level. At clinical follow-up examination, the patient had improved physical examination (Fig. 11).

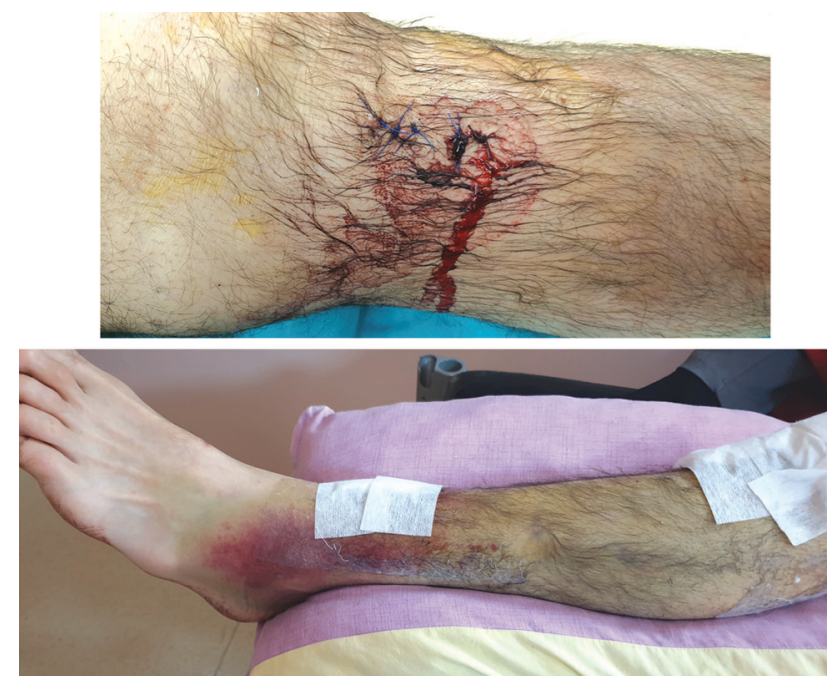

Fig. 1171 year-old male with distal tibial fracture (AO/ OTA 43A1), showing varicose veins
Group 6 A 60 years-old female patient was referred to our trauma center with a proximal humeral fracture. The patient was operated using plate osteosynthesis and screws via a minimal invasive procedures. In the operation room, bleeding as infiltration was observed during all the operation time (Fig. 12). The patient was questioned for anticoagulation therapy. The patient and her daughter reported ginger tea drinking for a month.

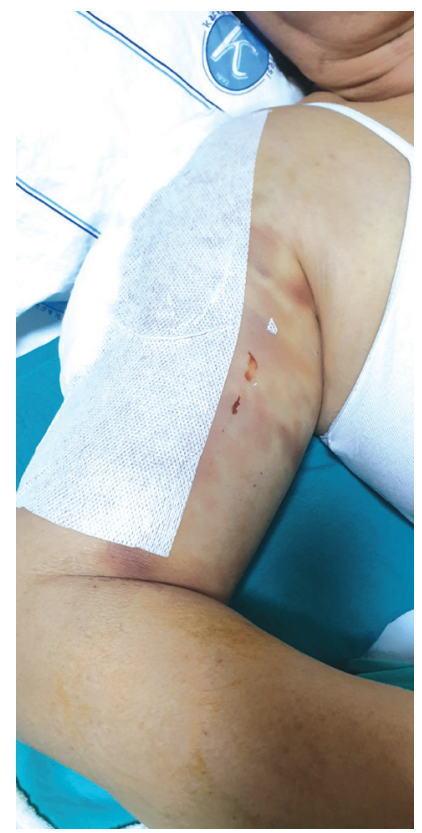

Fig. 1260 year-old female patient with a proximal humeral fracture; infiltration bleeding (extensive ginger tea taken during a month prior to surgery)

\section{DISCUSSION}

Patients suspected for bleeding diseases must be closely questioned at anamnesis (e.g. epistaxis, oral injuries, dental extractions and menorrhagia, etc.). Also, information on family history, malignancy, uraemia, parturition, hepatic cirrhosis, transfusions, collagen vascular disorders, and dietary habits or antibiotic use (vitamin $\mathrm{K}$ deficiency) must be ascertained [1]. All mucocutaneous bleeding patterns are important for diagnosis [5].

As part of the pathophysiology of VWD and BernardSoulier disease (BSD), PLT adhesion dysfunction is indicated [1]. In some populations, the VWD prevalence is approximately $1-3 \%$ [6]. VWD is a genetic and multifactorial disease, shows an autosomal dominant inheritance pattern [7], and is the most frequent inherited bleeding disease [8]. Plasma levels of Von Willebrand factor (VWF) are typically low. Certain factors exacerbate VWF levels, e.g. gravida, oestrogen, progesterone, glucocorticoids, adrenalin increases (e.g. stress and fear), hard physical exercise, hyperthyroidism, inflammatory diseases, vasculitis, diabetes mellitus, liver/kidney diseases; however hypothyroidism and valproic acid decrease VWD. Populations with the O Rhesus blood group show reduced VWF levels, as much as $25 \%$.

The effects of VWF deficiency during orthopaedic operations are not well documented in the literature [9]. VWD has been described after vascular surgeries, coronary artery grafts, liver and renal transplants and abdominal surgeries. VWD may cause persistent bleeding during operations and postoperative periods
[10]. In most cases, VWD is regarded as a single episode, with chronic frequent relapses [11], and patients should be followed-up long-term [12]. Nose and gingival bleeds, heavy menstrual periods, bruising and post-surgical/posttraumatic bleeding may be observed. Type I VWD is the mildest disease, Type II involves increasing symptoms and Type III is the severest type. It was observed that VWD prevalence was $0.6 \%$ [13]. In Type I, there is a partial lack of VWF (75-80\% of all types; VWF levels > 30 \%). Type 2 disease occurs when VWF exhibits structural (quantitative) abnormalities. Type 2 (1-30\% VWF levels) is comprised of four subtypes; $2 \mathrm{~A}(15-20 \%), 2 \mathrm{~B}(5 \%)$, $2 \mathrm{M}$ (very rare) and $2 \mathrm{~N}$ (autosomal recessive inheritance). Type 3 is defined as the complete absence of VWF (VWF levels $<1 \%$, i.e. autosomal recessive inheritance). If the patient has VWF levels < $30 \mathrm{IU} / \mathrm{dl}$, significant bleeding may occur, however if levels are $0-50 \mathrm{IU} / \mathrm{dl}$, the disease cannot be diagnosed unless bleeding occurs [14].

VWF is a haemostatic protein produced by endothelial cells and megakaryocytes, with the following functions: i) it forms bridges between damaged vascular structures and PLTs and ii) it stabilises factor VIII. VWF acts during PLT adhesion to expose collagen in damaged vascular endothelial area. The D1 and D2 domains help build the VWF pro-peptide, which is cleaved to produce the mature VWF [15].

VWD exhibits three VWF level defects, comprising; Type 1 (VWF levels < 50 IU/dl), Type 2 showing qualitative defects (variant VWF levels) and Type 
3, totally defective (undetectable VWF levels) [16]. Diagnostic tests include activated partial thromboplastin time (aPTT), bleeding time (BT), factor VIII:C ristocetin cofactor (FVIII:C ristocetin) and VWF antigen. Ristocetin-induced PLT adhesion (RIPA), multimeric structure and collagen-binding test and gen-analysis are made for diagnosis [16].

Definitive diagnoses are made using the following parameters: i) mucocutaneous bleeding, ii) low levels of VWF, iii) family history/anamnesis. Treatment should consist of local haemostatics, anti-fibrinolytics, hormonal therapy and replacement coagulation-helper products. Local haemostasis is performed by physical localised pressure, sponge gels and Surgicel. Tranexamic acid (Transamin) acts as an anti-fibrinolytic and is used at $250-500 \mathrm{mg}$ doses. The oestrogen analogue, LHRH may also be used. Similarly, for replacement therapy, fresh frozen plasma (FFP), cryoprecipitates, factor VIII/VWF concentrations and PLT transfusions may be performed [17].

One study included 1218 participants who were evaluated for VWF levels, where ristocetin cofactor activity of VWF was measured using the Macfarlane method [18]. Also, the Newman Keuls test demonstrated lower levels of VWF. In this study group, the male/ female ratio was 1.0. In terms of clinical symptoms, epistaxis accounted for $38 \%$, bleeding via extraction was $20 \%$, menorrhagia was $18 \%$, postpartum haemorrhage was $8 \%$, prolonged bleeding after superficial injuries was $4 \%$, tonsillectomy/adenoidectomy was $4.5 \%$, after surgery was $3.5 \%$, easy bruising was $2 \%$ and others were $1 \%$. The incidence in the population is unknown. Miller et al. classified as symptomatic as many as $23 \%$ of normal subjects [19].

BSD is characterised by defective PLT binding to collagen, and the inability of the PLT membrane glycoprotein, GPIb-IX-V complex to adhere to VWF [20]. ITP (also known as primary immune thrombocytopenia) is an acquired bleeding disease. Peripheral PLT counts are $<100,000$ cells/ $\mu 1[21,22]$. Auto-antibodies destruct PLTs [23].

In the largest fracture study in persons with haemophilia (PWH), Caviglia et al. established a higher incidence of LL (lower limb) fractures in the period 1986-1990. The ratio LL/UL changed as UL (upper limb) fractures became more frequent. These authors showed that treatments decreased orthopaedic complications, and improved the quality of life in PWH [24].

In another study, a rare haemophilia disease was identified from bleeding complications after an orthopaedic surgery, and diagnosed as Thrombotic Thrombocytopenic Purpura (TTP) [25]. Iosifidis et al. proposed treatments including; 1) urgent plasma exchange, 2) plasmapheresis, 3) initial treatment with plasma infusion and glucocorticoids, 4) plasma infusion, 5) $\gamma$-globulin or glucocorticoid administration, and 6) antiplatelet drugs (dipyridamole and aspirin). If desired outcomes were not forthcoming, plasma exchange was repeated twice daily. These authors emphasised that TTP (Moschowitz's syndrome) was a rare, life-threatening disease, with a mortality rate approaching $80-90 \%$, especially during orthopaedic operations where greater bleeding frequencies were often observed. They suggested that orthopaedists should be alert to TTP [25], and for mild forms, the synthetic agent, desmopressin, could be indicated [16].

Haemophilia diseases are $\mathrm{X}$-linked recessive disorders. Haemophilia A is defined as factor VIII deficiency, while haemophilia B exhibits factor IX deficiency. The clinical manifestations of haemophilia are typically observed in men, in 1/5000-1/50,000 male births [26, 27]. Factor activity levels are defined as mild, with $>5 \%$ activity, moderate at $1-5 \%$ activity, or severe at $<1 \%$ activity. The classifications match the clinical symptoms. Haemophilia may lead to chronic haemophilic arthropathy and arthrofibrosis, whereas other complications include compartment syndrome, infection and pseudo-tumours [28, 29].

\section{Secondary bleeding diseases}

Drugs such as aspirin, non-steroidal anti-inflammatory drugs (NSAIDs), clopidogrel and herbals, and the condition, uraemia, can limit PLT function. Aspirin inhibits PLTs by the acetylation of PLT cyclooxygenase- 1 (COX-1), and inhibition of thromboxane A2 (TXA2) synthesis. The incidence of minor bleeding is $5 \%-10 \%$, whereas major bleeding is 1-2 \% [30]. Thienopyridines, such as clopidogrel, ticlodipine and prasugrel antagonise adenosine diphosphate (ADP) stimulation, both selectively and irreversibly [31, 32]. Herbal preparations such as ginkgo biloba, garlic, and ginseng can interfere with blood clotting by affecting PLT function. Other medications such as ginger, feverfew, clove, kava kava, white willow bark may also affect clotting functions. Other suspected supplements may include vitamins A and E and fish oil [33]. Thrombo-philias, liver disease, vitamin $\mathrm{K}$ deficiency are the other secondary bleeding causes. Desmopressin $(0.3 \mu \mathrm{g} / \mathrm{kg})$ may be used and vitamin $\mathrm{K}$ administration (1 to $25 \mathrm{mg}$ ) excludes deficiency [34]. The clotting factors II, VII, IX, and X, as well as proteins C and $\mathrm{S}$ require vitamin $\mathrm{K}$ [35].

Other medications such as heparin, low-molecularweight heparin, warfarin, and direct thrombin inhibitors are also other causes of secondary haemostasis [36]. Rivaroxaban and apixaban inhibits and binds directly to factor Xa, blocking its interaction with substrates [37]. Unfractionated heparin (UFH) inactivates thrombin, and factors VIIa, IXa, Xa, and XIa. Low-molecularweight heparin, such as enoxaparin, inactivates factor $\mathrm{Xa}$ and should be preoperatively stopped at 12-24 hours [38]. Warfarin inhibits factors II, VII, IX, X and the anticoagulant proteins $\mathrm{C}$ and $\mathrm{S}$, and it inactivates vitamin $\mathrm{K}$-dependent $\gamma$-carboxylation of pro-coagulant factors [39]. Warfarin may be resumed postoperatively after 12-24 hours [30].

\section{Orthopaedic clinics and bleeding disorders}

Barg et al. studied 34 patients with ankle osteoarthritis (14 haemophilia Type A, and 20 with VWD) treated with total ankle replacement. They showed that patient groups with bleeding diseases had significantly higher pain relief, and significantly lower ROM than control groups, with normal ankles [40]. Zulfikar et al. stated that VWD 
management was difficult because of bleeding; and that perioperative and postoperative patients must be monitored closely and carefully [41]. Vascular malformations can cause problems in some orthopaedic surgeries, e.g. bleeding, pain, deformity and functional limitations, with such patients also showing cardiovascular and haematological abnormalities. In vascular abnormalities, thromboembolic diseases are increased, wound infections are more common, and bleeding may continue during the postoperative course [42]. In a study investigating 168 arthroplasties (79 knees, 30 hips, three ankles and one elbow), in the congenital coagulation disorder group, spontaneous intraarticular bleedings resulted in damage to the joints and periarticular structures [43]. Accordingly, this study recommended that orthopaedic and haematological teams must evaluate these patients, both preoperatively and postoperatively [43]. Between 1997 and 2014, 825 surgical procedures were undertaken in 286 severe haemophilic patients [44]. A study compared post-operative standard rehabilitation (SR) and plus water rehabilitation (WR) in patients with haemophilia, undergoing total joint replacement.
184 patients [(233 rehabilitation programs; 160 total knee replacements (TKR), 37 total ankle replacements (TAR) and 36 total hip replacements (THR)]. 28 (25\%) patients were treated with WR in addition to SR (32 for TKR, 19 for TAR and seven for THR), with an average 5.7 hours for WR. Muscle strength, pain and perceived health status improved significantly [45]. Erturan et al. reviewed 20 years of publications on haemophilia patients with inhibitors, undergoing orthopaedic surgical operations, and found that patients with bleeding disorders were concerns for medical care when considering the benefits in quality of life against the prevalent complications [46].

Mansour et al. recommended the following for coagulopathic orthopaedic patients: i) a careful patient's history, mandatory physical examination and laboratory evaluations and ii) primary and secondary haemostasis must be comprehensively ascertained. They also emphasised that clinical bleeding disorder presentations must be well documented, but their most important point was the multidisciplinary approach of haematologists, cardiologists and surgeons [1].

\section{CONCLUSIONS}

A careful history (patient's anamnesis), full-featured physical examination, and all laboratory tests on bleeding diseases must be provided before orthopedic surgical procedures. Counts and functions of platelets, all bleeding tests and all medications taken by the patient are important for effective preoperative preparation for an orthopaedic operation. A multidisciplinary team that consists of surgeons, hematologists, and cardiovascular specialists must be organized in all hospitals. As the first step, a total blood count (must include the platelet counts), prothrombin time (PT), and activated partial thromboplastin time (aPTT) are the screening methods. At the next steps, other laboratory tests must be applied for detecting bleeding diseases.

We advise to make a preoperative careful control for postsurgical bleeding risks according to three criteria: i) patient's anamnesis should be taken carefully (diathesis/ hemophilia search); ii) platelet counts must be studied (twice is guaranteed); iii) coagulation tests [activated partial thromboplastin time (aPTT), prothrombin time (PT), thrombin time (TT) and international normalized ratio (INR)] must be included.

Conflict of Interest The authors declare that they have no conflict of interest.

Funding There is no funding source.

Ethical approval This article does not contain any studies with human participants or animals performed by any of the authors.

Informed consent Informed consent was obtained from all individual participants included in the study.

\section{REFERENCES}

1. Mansour J., Graf K., Lafferty P. Bleeding disorders in orthopedic surgery. Orthopedics, 2012, vol. 35, no. 12, pp. 1053-1062. DOI: 10.3928/0147744720121120-09.

2. Doherty T.M., Kelley A. Bleeding Disorders. Treasure Island (FL), StatPearls Publishing. 2020.

3. Oberweis B.S., Nukala S., Rosenberg A., Guo Y., Stuchin S., Radford M.J., Berger J.S. Thrombotic and bleeding complications following orthopedic surgery. Am. Heart J., 2013, vol. 165, no. 3, pp. 427-433. E1. DOI: 10.1016/j.ahj.2012.11.005.

4. Bolton-Maggs P.H., Chalmers E.A., Collins P.W., Harrison P., Kitchen S., Liesner R.J., Minford A., Mumford A.D., Parapia L.A., Perry D.J., Watson S,P., Wilde J.T., Williams M.D. A review of inherited platelet disorders with guidelines for their management on behalf of the UKHCDO. Br. J. Haematol., 2006, vol. 135, no. 5, pp. 603-633. DOI: 10.1111/j.1365-2141.2006.06343.x

5. Greaves M., Watson H.G. Approach to the diagnosis and management of mild bleeding disorders. J. Thromb. Haemost., 2007, vol. 5, no. Suppl. 1, pp. 167174. DOI: 10.1111/j.1538-7836.2007.02495.x.

6. Kroonen L.T., Gillingham B.L., Provencher M.T. Orthopedic manifestations and management of patients with von Willebrand disease. Orthopedics, 2008, vol. 31, no. 3, pp. 263-269. DOI: 10.3928/01477447-20080301-22.

7. Sultan Y., Caen J., Bernard J. Demonstration of recessive transmission in Willebrands diseases. Detection of heterozygotes. C. R. Acad. Hebd. Seances Acad. Sci. $D, 1974$, vol. 279 , no. 13 , pp. 1139-1142.

8. Lavin M., O'Donnell J.S. How I treat low von Willebrand factor levels. Blood, 2019, vol. 133, no. 8, pp. 795-804. DOI: 10.1182/blood-2018-10-844936.

9. Mansour J., Graf K., Lafferty P. Bleeding disorders in orthopaedic surgery. Orthopaedics, 2012, no. 35(12), pp. 1053-1062.

10. Gopinath R., Sreekanth Y., Yadav M. Approach to bleeding patient. Indian J. Anaesth., 2014, vol. 58, no. 5, pp. 596-602. DOI: 10.4103/0019-5049.144664.

11. Diez-Zapirain M.A., Iruin-Irulegui G., Rabanal A., Matorras R. Recurrent Hemoperitoneum after Oocyte Pick-Up in an IVF Patient with Von Willebrand Disease May be Prevented with a Combination of Factor VIII and Von Willebrand Factor. Int. J. Reprod. Med. Gynecol., 2019, vol. 5, no. 1, pp. 001-003.

12. Heijdra J.M., Cnossen M.H., Leebeek F.W.G. Current and Emerging Options for the Management of Inherited von Willebrand Disease. Drugs, 2017 , vol. 77, no. 14, pp. 1531-1547. DOI: 10.1007/s40265-017-0793-2.

13. Gill J.C., Shapiro A., Valentino L.A., Bernstein J., Friedman C., Nichols W.L., Manco-Johnson M. Von Willebrand factor/factor VIII concentrate (Humate-P) for management of elective surgery in adults and children with von Willebrand disease. Haemophilia, 2011, vol. 17, no. 6, pp. 895-905. DOI: 10.1111/j.1365-2516.2011.02534.x. 
14. Higasa S., Tokugawa T., Sawada A. Diagnosis and management of Von Willebrand disease. Rinsho Ketsueki, 2018, vol. 59, no. 10, pp. $2222-2232$. DOI: 10.11406/rinketsu.59.2222.

15. Keesler D.A., Flood V.H. Current issues in diagnosis and treatment of von Willebrand disease. Res. Pract. Thromb. Haemost., 2017, vol. 2, no. 1, pp. 34-41. DOI: $10.1002 /$ rth2.12064.

16. Echahdi H., El Hasbaoui B., El Khorassani M., Agadr A., Khattab M. Von Willebrand's disease: case report and review of literature. Pan Afr. Med. J., 2017, vol. 27, p. 147. DOI: 10.11604/pamj.2017.27.147.12248.

17. Turkiz G. Von Willebrand Disease Basic Hemostasis Thrombosis Course Book. Gazi University, Turk Hematology Society. 2007, pp. 52-59.

18. Macfarlane D.E., Stibbe J., Kirby E.P., Zucker M.B., Grant R.A., McPherson J. Letter: A method for assaying von Willebrand factor (ristocetin cofactor). Thromb. Diath. Hemorrh., 1975, vol. 34, no. 1, pp. 306-308.

19. Miller C.H., Graham J.B., Goldin L.R., Elston R.C. Genetics of classic von Willebrand’s disease. I. Phenotypic variation within families. Blood, 1979, vol. 54, no. 1, pp. 117-136.

20. Simon D., Kunicki T., Nugent D. Platelet function defects. Haemophilia, 2008, vol. 14, no. 6, pp. 1240-1249. DOI: 10.1111/j.1365-2516.2008.01898.x.

21. Provan D., Stasi R., Newland A.C., Blanchette V.S., Bolton-Maggs P., Bussel J.B., Chong B.H., Cines D.B., Gernsheimer T.B., Godeau B., Grainger J., Greer I., Hunt B.J., Imbach P.A., Lyons G., McMillan R., Rodeghiero F., Sanz M.A., Tarantino M., Watson S., Young J., Kuter D.J. International consensus report on the investigation and management of primary immune thrombocytopenia. Blood, 2010, vol. 115, no. 2, pp. 168-186. DOI: 10.1182/blood-2009-06-225565.

22. Rodeghiero F., Stasi R., Gernsheimer T., Michel M., Provan D., Arnold D.M., Bussel J.B., Cines D.B., Chong B.H., Cooper N., Godeau B., Lechner K., Mazzucconi M.G., McMillan R., Sanz M.A., Imbach P., Blanchette V., Kühne T., Ruggeri M., George J.N. Standardization of terminology, definitions and outcome criteria in immune thrombocytopenic purpura of adults and children: report from an international working group. Blood, 2009, vol. 113, no. 11, pp. 2386-2393. DOI: 10.1182/blood-2008-07-162503.

23. Olsson B., Andersson P.-O., Jernås M., Jacobsson S., Carlsson B., Carlsson L.M.S., Wadenvik H. T-cell-mediated cytotoxicity toward platelets in chronic idiopathic thrombocytopenic purpura. Nat. Med., 2003, vol. 9, no. 9, pp. 1123-1124. DOI: 10.1038/nm921.

24. Caviglia H., Landro M.E., Galatro G., Candela M., Neme D. Epidemiology of fractures in patients with haemophilia. Injury, 2015, vol. 46, no. 10, pp. 1885-1890. DOI: 10.1016/j.injury.2015.06.034.

25. Iosifidis M.I., Ntavlis M., Giannoulis I., Malioufas L., Ioannou A., Giantsis G. Acute thrombotic thrombocytopenic purpura following orthopedic surgery: a case report. Arch. Orthop. Trauma Surg., 2006, vol. 126, no. 5, pp. 335-338. DOI: 10.1007/s00402-005-0014-4.

26. Lasne D., Jude B., Susen S. From normal to pathological hemostasis. Can. J. Anaesth., 2006, vol. 53, no. 6 Suppl., pp. S2-S11. DOI: $10.1007 / b f 03022247$.

27. Van Dijk K., Fischer K, van der Born J.G., Grobbee D.E., van den Berg H.M. Variability in clinical phenotype of severe haemophilia: the role of the first joint bleed. Haemophilia, 2005, vol. 11, no. 5, pp. 438-443. DOI: 10.1111/j.1365-2516.2005.01124.x.

28. Roosendaal G., Lafeber F.P. Pathogenesis of haemophilic arthropathy. Haemophilia, 2006, vol. 12, no. Suppl. 3, pp. 117-121. DOI: 10.1111/j.13652516.2006.01268.x.

29. Van den Berg H.M., Fischer K., Mauser-Bunschoten E.P., Beek F.J., Roosendaal G., van der Bom J.G., Nieuwenhuis H.K. Long-term outcome of individualized prophylactic treatment of children with severe haemophilia. Br. J. Haematol., 2001, vol. 112, no. 3, pp. 561-565. DOI: 10.1046/j.13652141.2001.02580.x.

30. Cattaneo M. Aspirin and Clopidogrel: efficacy, safety, and the issue of drug resistance. Arterioscler. Thromb. Vasc. Biol., 2004, vol. 24, no. 11, pp. 19801987. DOI: 10.1161/01.ATV.0000145980.39477.a9.

31. Gayle J., Kaye A.D., Kaye A.M., Shah R. Anticoagulants: new ones, mechanisms, and perioperative updates. Anesthesiol. Clin., 2010, vol. 28, no. 4, pp. 667-679. DOI: 10.1016/..anclin.2010.08.013.

32. Horlocker T., Wedel D.J., Rowlingson J.C., Enneking F.K., Kopp S.L., Benzon H.T., Brown D.L., Heit J.A., Mulroy M.F., Rosenquist R.W., Tryba M., Yuan C-S. Regional anesthesia in the patient receiving antithrombotic or thrombolytic therapy: American Society of Regional Anesthesia and Pain Medicine Evidence-Based Guidelines (Third edition). Reg. Anesth. Pain Med., 2010, vol. 35, no. 1, pp. 64-101. DOI: 10.1097/aap.0b013e3181c15c70.

33. Ang-Lee M.K., Moss J., Yuan C.S. Herbal medicines and perioperative care. JAMA, 2001, vol. 286, no. 2, pp. 208-216. DOI: 10.1001/jama.286.2.208

34. Lisman T., Porte R.J. Rebalanced hemostasis in patients with liver disease: evidence and clinical consequences. Blood, 2010, vol. 116, no. 6, pp. 878-885. DOI: 10.1182/blood-2010-02-261891.

35. Dagi T.F. The management of postoperative bleeding. Surg. Clin. North Am., 2005, vol. 85, no. 6, pp. 1191-1213-x. DOI: 10.1016/j.suc.2005.10.013.

36. Garwood C.L., Gortney J.S., Corbett T.L. Is there a role for fondaparinux in perioperative bridging? Am. J. Health Syst. Pharm., 2011, vol. 68, no. 1, pp. 36-42. DOI: 10.2146/ajhp100133.

37. Weitz J.I., Hirsch J., Samama M.M. New antithrombotic drugs: American College of Chest Physicians Evidence-Based Clinical Practice Guidelines $\left(8^{\text {th }}\right.$ edition). Chest, 2008, vol. 133, no. 6 Suppl., pp. 234S-256S. DOI: 10.1378/chest.08-0673.

38. Levi M.M., Eerenberg E., Löwenberg E., Kamphuisen P.W. Bleeding in patients using new anticoagulants or antiplatelet agents: risk factors and management. Neth. J. Med., 2010, vol. 68, no. 2, pp. 68-76.

39. Dhinsa B., Khan W.S., Tailor H. Management of anticoagulation therapy in the perioperative patient. J. Perioper. Pract., 2011, vol. 21, no. 8, pp. $279-283$. DOI: 10.1177/175045891102100804.

40. Barg A., Barg K., Wiewiorski M., Schneider S.W., Wimmer M.D., Wirtz D.C., Valderrabano V., Pagenstert G. Total ankle replacement in patients with bleeding disorders. Orthopade, 2015, vol. 44, no. 8, pp. 623-638. DOI: 10.1007/s00132-015-3107-y.

41. Zulfikar B., Koc B., Ak G., Dikici F., Karaman İ., Atalar A.C., Bezgal F. Surgery in patients with von Willebrand disease. Blood Coagul. Fibrinolysis, 2016, vol. 27, no. 7, pp. 812-816. DOI: 10.1097/MBC.0000000000000500.

42. Spencer S.A., Sorger J. Orthopedic issues in vascular anomalies. Semin. Pediatr. Surg., 2014, vol. 23, no. 4, pp. 227-232. DOI: 10.1053/j. sempedsurg.2014.06.015.

43. Kotela I., Żbikowski P., Ambroziak P., Kotela A., Lorkowski J., Stefańska-Windyga E., Wojdasiewicz P., Latawiec F., Windyga J. Orthopedic procedures in patients with congenital coagulation disorders: single center experience. Ortop. Traumatol. Rehabil., 2013, vol. 15, no. 6, pp. 601-616. DOI: 10.5604/15093492.1091516.

44. Andersen M.F., Holme P.A., Tjønnfjord G.E. Surgical procedures in patients with severe haemophilia 1997-2014. Tidsskr. Nor. Laegeforen, 2019, vol. 139, no. 8. DOI: 10.4045 /tidsskr.18.0592.

45. Passeri E.V., Martinelli M., Gatteri V., Pivetti S., Passeri C., Cigolini L., Chiari S., Zenorini A., Gaffurini P., Bernardi S., Poli I., Bissolotti L. Standard and water rehabilitation: An analysis of over 14 years' experience in patients with haemophilia or other clotting factor disorders after orthopaedic surgery. Haemophilia, 2019, vol. 25, no. 4, pp. 699-707. DOI: 10.1111/hae.13748.

46. Erturan G., Guevel B., Alvand A., Goddard N.J. Over two decades of orthopaedic surgery in patients with inhibitors - Quantifying the complication of bleeding. Haemophilia, 2019, vol. 25, no. 1, pp. 21-32. DOI: 10.1111/hae.13647.

Received: 05.02.2020

\section{Information about the authors:}

1. Kadri Yildiz, M.D., Assist. Prof., Kafkas University, Medicine School, Kars, Turkey,

Email: drkadri1980@hotmail.com, ORCID: 0000-0002-8164-7687

2. Vahit Yildiz, M.D., Assist. Prof., Adnan Menderes University, Medicine School, Aydın, Turkey 